\title{
FEM Simulation and Experimental Validation of Cold Forging Behavior of LM6 Base Metal Matrix Composites
}

\author{
Hillol Joardar ${ }^{*}$, Goutam Sutradhar ${ }^{2}$, Nitai Sudar Das ${ }^{1}$ \\ ${ }^{1}$ Department of Mechanical Engineering, C.V. Raman College of Engineering, Bhubaneswar, Orissa, India \\ ${ }^{2}$ Department of Mechanical Engineering, Jadavpur University, Kolkata, West Bengal, India

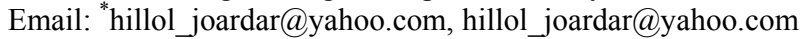

Received August 15, 2012; revised September 20, 2012; accepted September 30, 2012

\begin{abstract}
The present paper examines the deformation behavior of solid cylinders of an aluminium alloy metal matrix composite (MMC) undergoing axial compression in a Universal Testing Machine under dry condition. The composite was prepared by the stir casting method from LM6 aluminium alloy using silicon carbide particles ( $\mathrm{SiC})$ as reinforcing agent. The effect of weight percentage of silicon carbide on microstructure, hardness and upsetting load is studied. The friction factor at die metal interface is evaluated by ring compression tests and its effect on non-uniform deformation is investigated. The experimental results are finally compared with those obtained by FEM simulation.
\end{abstract}

Keywords: LM6-SiC MMC; Hardness; Microstructure; Forging; FEM

\section{Introduction}

In recent years considerable attention has been directed to the study of aluminium metal matrix composites because of their growing applications in aerospace and automotive industries [1,2]. This is not only due to their superior mechanical and thermal properties (high specific strength, excellent wear resistance, high thermal conductivity $[2,3]$ ) but is also to a large extent due to the fact that these properties can be manipulated by careful control of the relative amounts and distribution of the ingredients and the processing conditions to suit specific requirements [2].

Metal matrix composites can be produced by the powder metallurgy method [4,5], by spray deposition technique [6] and by stir casting [7-11]. For discontinuous metal matrix composites the last method is generally accepted as a particularly promising route currently practiced commercially. Its advantages lie in its simplicity, flexibility and applicability to large quantity production at relatively low cost.

Presence of silicon carbide particles influences the mechanical properties and the deformation behavior of the aluminium metal matrix in a number of ways. The proof stress $(0.2 \%)$ and ultimate tensile strength of aluminium tend to increase while its toughness and ductility decrease as the volume fraction of $\mathrm{SiC}$ particles in the

${ }^{*}$ Corresponding author. matrix increases or when its particle size decreases [12]. The brittle fracture behavior of these composites is also found to be affected by the weight fraction of the reinforcing agent [13]. Secondary processing and heat treatment operations are seen to contribute to the performance of these materials. Thus crack formation in axial compression of $\mathrm{Al} / \mathrm{SiC}$ solid cylinders made by powder metallurgy is found to be suppressed by subjecting these cylinders to an annealing or quenching treatment prior to the deformation process [14]. Parts having undergone forming operations such as forging and extrusion tend to have refine grain structure resulting in their improved performance. It must be stated, however that most of the studies on mechanical behavior and material characterization of Aluminium-SiC metal matrix composites have been limited to materials prepared by powder metallurgy. For composites prepared by ingot metallurgy similar studies are relatively less.

In the present investigation an attempt is made to evaluate the effect of $\mathrm{SiC}$ particles on the microstructure and mechanical behavior of an aluminium alloy composite (LM6/SiC) made by stir casting. Microstructure studies of caste samples have been carried out using an optical microscope to look into the degree of wettability and segregation of the reinforcing particles. Microhardness and compression tests were also performed to study the effect of $\mathrm{SiC}$ on the forgeability of caste metal matrix. The experimental results are finally compared 
with those obtained by finite element simulation.

\section{Experimental Procedure}

\subsection{Materials and Method}

The composite for the present study was prepared from LM6 aluminium alloy using silicon carbide particles (approximately 400 mesh size) as reinforcing agents. The aluminium alloy was first melted in a resistance furnace and $3 \mathrm{wt} \%$ of magnesium was subsequently added to the molten metal. This was because magnesium is known to favour formation of a strong bond between the matrix and the reinforcing particles by decreasing the surface energy (wetting angle). Addition of pure magnesium also enhances the fluidity of molten aluminium. Preheated $\mathrm{SiC}$ particles (temperature $850^{\circ} \mathrm{C}-900^{\circ} \mathrm{C}$ ) in varying weight fractions $(5 \mathrm{wt} \%-12.5 \mathrm{wt} \%)$ was then added to the melt and the mix was mechanically stirred at a temperature of $750^{\circ} \mathrm{C}$ by an impeller at a stirring speed of about $400 \mathrm{rpm}-500 \mathrm{rpm}$. The melt was poured at a temperature of $745^{\circ} \mathrm{C}$ into silica sand moulds for preparation of the test samples. The composition of LM6 alloy is given in "Table 1".

\subsection{Microscopy}

For microscopic examination specimens of cast composites of $10 \mathrm{~mm}$ diameter and $15 \mathrm{~mm}$ thickness were first ground through 320, 400, 600, 800, 1200 and 1500 grit emery papers followed by polishing by $6 \mu \mathrm{m}$ diamond paste. The samples were then etched with Keller's reagent $(2.5 \mathrm{ml} \mathrm{HNO}, 1.5 \mathrm{ml} \mathrm{HCl}, 1.0 \mathrm{ml} \mathrm{HF}, 95.0 \mathrm{ml}$ Water) and dried by an electric drier. The microstructure was observed by a metallurgical microscope (Olympus, CK40M).

\subsection{Hardness Measurements}

Micro-hardness measurements were also carried out using a LEICA VMHT micro-hardness tester at 100 gms load with a dwell time of 10 seconds to study the variation of hardness with different $\mathrm{wt} \%$ of $\mathrm{SiC}$.

\subsection{Compression Test}

For forgeability tests, cylindrical specimens of L/D ratio equal to 1.5 (height $\mathrm{L}=15 \mathrm{~mm}$, Diameter $\mathrm{D}=10 \mathrm{~mm}$ ) were compressed axially on a 100-ton hydraulic press at room temperature under dry condition. To plot the stressstrain diagram, the tests were interrupted at every $5 \mathrm{~mm}$ reduction in height and the corresponding load $P$ and the equatorial diameter $D_{E}$ were measured. The stress $(\sigma)$ and the strain $(\varepsilon)$ were then calculated from the equations:

$$
\sigma=P / A_{E}
$$

where, $A_{E}=\pi / 4 D_{E}^{2}$ was the area of the equatorial plane and

$$
\varepsilon=\ln \left(L_{o} / L\right)
$$

where $L_{0}$ was the initial height and $L$ the current height of the cylinder. The tests were continued till cracks appeared at the free surface and was stopped when these cracks grew sufficiently large leading to the collapse of the specimens. The forgeability limit was taken to be the height strain at which the cracks were first observed on the free surface of the specimen.

\subsection{Finite Element Simulation}

Finite element simulation of the cold upsetting process under un-lubricated condition was carried out with the help of DEFORM-3D software using the Lagrangian formulation. The coefficient of friction required for the simulation was obtained from the ring compression test.

\subsection{Determination of Coefficient of Friction}

In metal forming interface friction plays an important role. It controls the magnitude of the redundant work, the magnitude of the metal forming load and the stress and strain distribution in the deforming medium. The interface friction may be quantified either by a friction factor $\mathrm{m}(\tau=m k, k=$ shear stress of work material) or a coefficient of friction $\mu$ (Coulomb's law, $\tau=\mu p$ ). In the present study Coulomb's law of friction was assumed at the interface between the die and the deforming billet and the coefficient of friction was determined by the ring compression test as suggested by Male \& Cockcroft [14]. Figure 1(a) shows [15] the calibration curves for determination of coefficient of friction and the geometry of a ring before and after compression is presented in Figure 1(b).

\section{Results and Discussions}

The microstructures of the caste and polished samples as revealed by a metallurgical microscope are presented in Figure 2. In these microstructures the dark areas represent the ceramic phase where as the metallic phase appears white. The microstructures show a reasonably uni-

\begin{tabular}{|c|c|c|c|c|c|c|c|c|c|c|c|}
\hline Elements & $\mathrm{Si}$ & $\mathrm{Cu}$ & $\mathrm{Mg}$ & $\mathrm{Fe}$ & $\mathrm{Mn}$ & $\mathrm{Ni}$ & $\mathrm{Zn}$ & $\mathrm{Pb}$ & $\mathrm{Sb}$ & $\mathrm{Ti}$ & $\mathrm{Al}$ \\
\hline $\begin{array}{c}\text { Percentage } \\
(\%)\end{array}$ & $10-13$ & 0.1 & 0.1 & 0.6 & 0.5 & 0.1 & 0.1 & 0.1 & 0.05 & 0.2 & Remaining \\
\hline
\end{tabular}

Table 1: Chemical composition (LM6). 


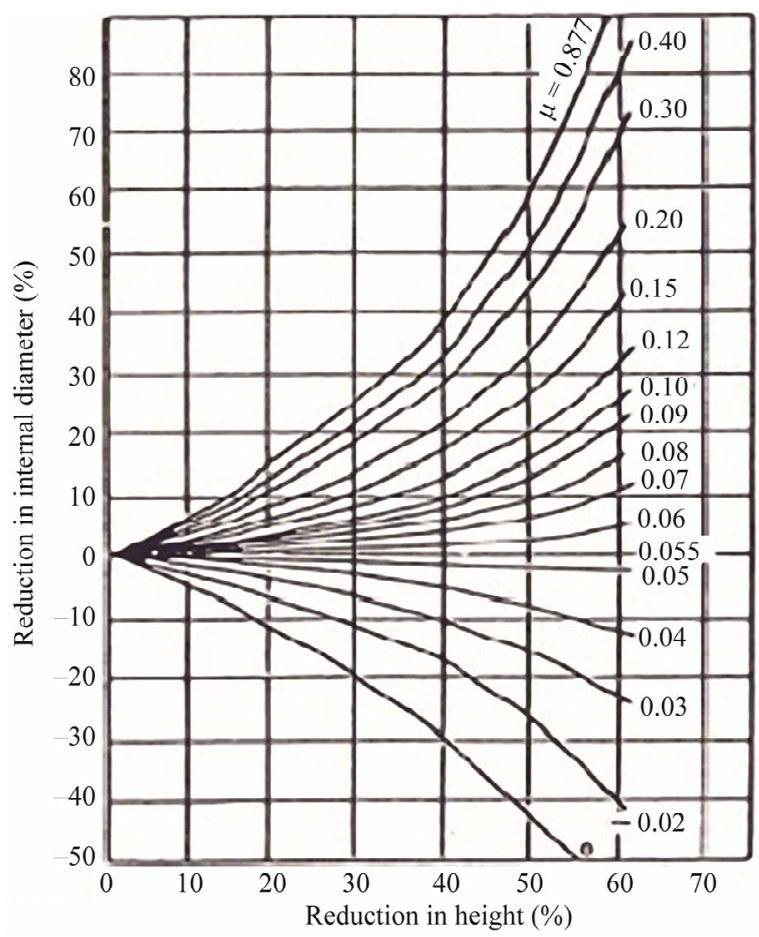

(a)
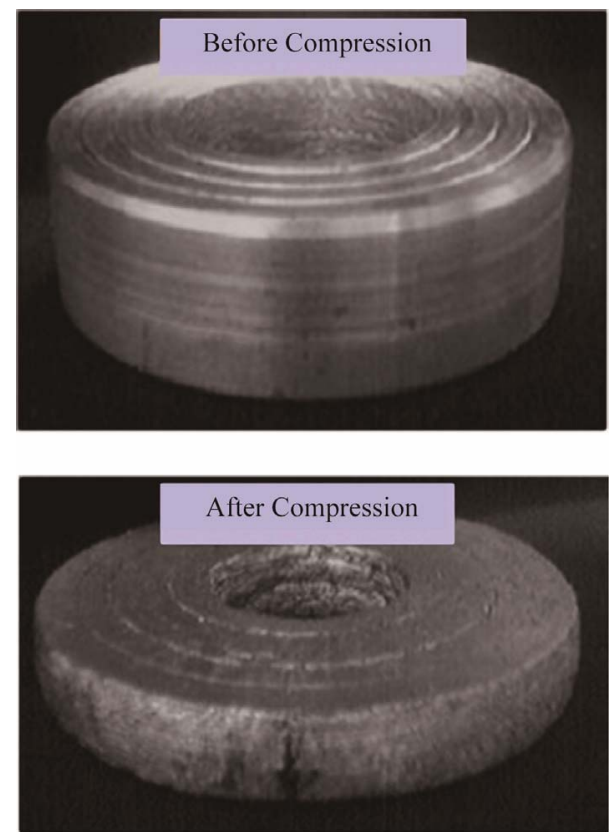

(b)

Figure 1. (a) Friction calibration curves in terms of coefficient of friction; (b) Ring compression specimen (a) before and (b) after compression.

form distribution of $\mathrm{SiC}$ particles in the matrix with only slight macro-segregation in some areas. This indicates good wetting of the silicon carbide particles by the molten metal and excellent interfacial bonding between the two phases.

The hardness (Figure 3) and the compressive strength

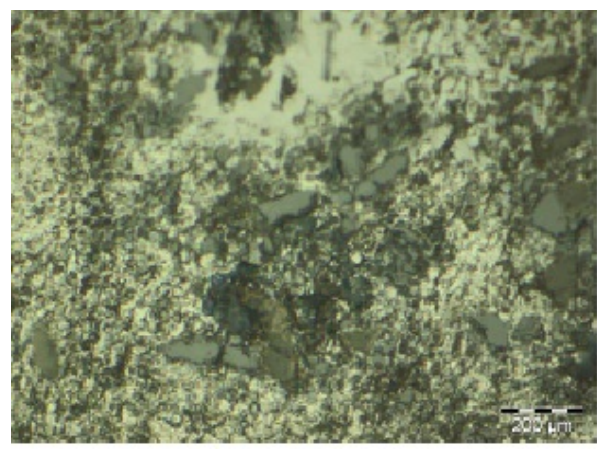

(a)

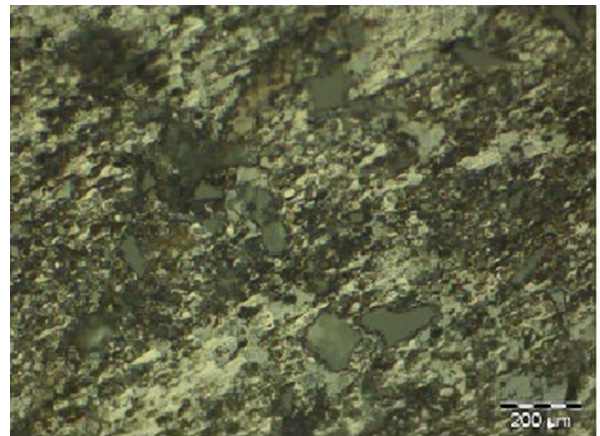

(b)

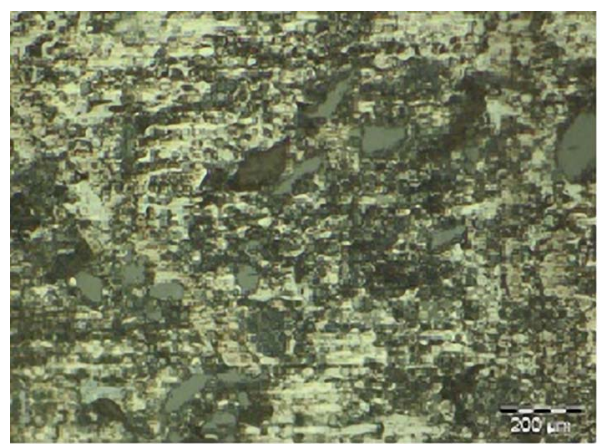

(c)

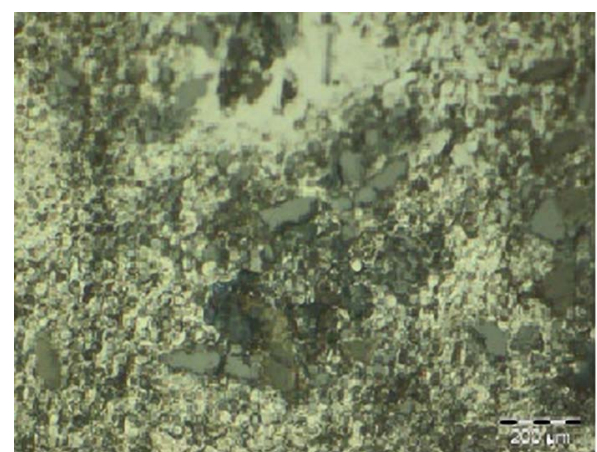

(d)

Figure 2. Microstructures of cast $\mathrm{LM6} / \mathrm{SiC}$ composites (a) $\mathrm{SiC}: 5 \%$; (b) SiC: $7.5 \%$; (c) SiC: $10 \%$; (d) SiC: $12.5 \%$.

(Figure 4) of the composites are found to increase with increase in the weight fraction of the reinforcing particles. The compressive strength here refers to the average axial stress $\sigma$ (Equation (1)) over the equatorial plane. The 


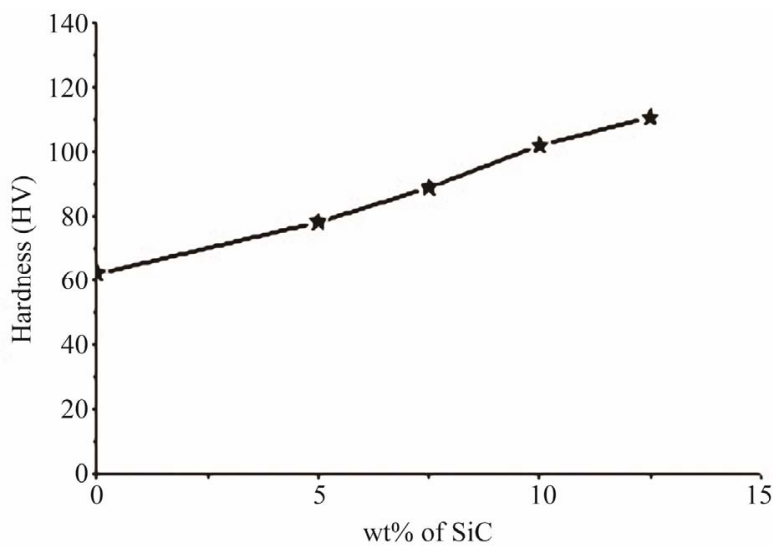

Figure 3.Variation of hardness with weight percentage of SiC.

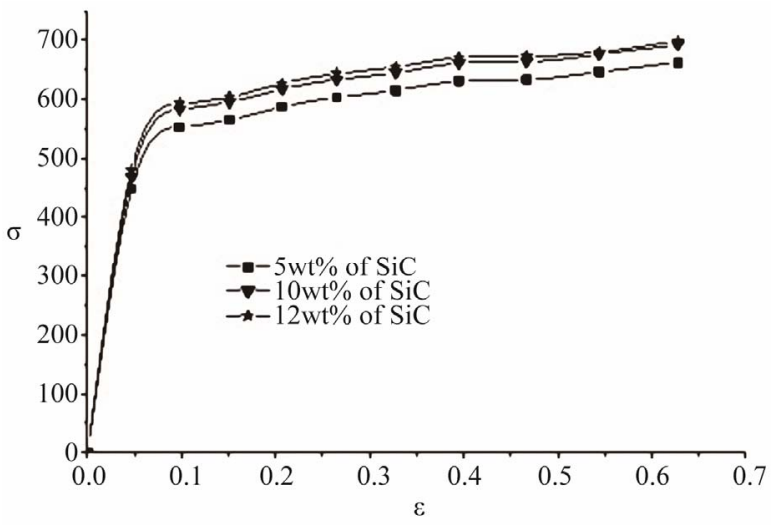

Figure 4. Variation of equatorial stress with height strain.

above increase may be due to the increase in dislocation density at the interfaces of the hard carbide particles and the soft metal matrix or may be the result of the incomepatibility in the elastic and the plastic behavior of the two phases due to their differential thermal expansion. A reduction in the grain size of the metal matrix due to addition of silicon carbide might also have contributed to this improvement in the mechanical properties.

Two types of cracks are seen in the forging of LM6 based composites. These are the speed cracks and the surface cracks. Friction at the interface between the die and the billet during axial compression results in inhomogenity of deformation and consequent barreling of the free surface of the billet. This gives rise to high tensile stresses leading to speed cracking. Surface tearing occurs when the surface temperature exceeds the melting temperature of the phase having the lowest melting point. In the present study surface tearing was observed at room temperature. This might be due to the conversion of work of compression into thermal energy resulting in temperature rise of the billets. It was also observed that cracks were initiated only after compression of the billets by about $28 \%-32 \%$ depending on the weight fraction of the $\mathrm{SiC}$. The specimens collapsed completely after a reduction in height by about $34 \%-38 \%$.

\section{FEM Simulation}

As a basis for comparison finite element simulation of the upsetting process was carried out using DEFORM3D software that uses implicit Lagrangian formulation for the analysis. For this purpose the material constitutive equation was assumed as:

$$
\sigma=K \varepsilon^{n}
$$

where $K$ is the stress coefficient, $n$ is the strain hardening index, $\sigma$ is the effective stress, $\varepsilon$ is the effective strain, $K$ and $n$ were both determined from compression tests and used for simulation.

The other data used for simulation were Poisson's ratio $\nu=0.33$ and coefficient of friction $\mu=0.34$.

The coefficient of friction was determined from the ring compression test as mentioned in 2.6.

The four-node quadrilateral elements with 3168 nodes and 3040 elements are adopted to discretise the cylinder and that of a cylinder before and after compression are shown in Figure 5.

In Figures 6 and 7 the experimentally measured parameters are compared with those obtained from the finite element simulation. The increase in radius of the equatorial plane with height reduction by both the methods show excellent agreement with each other (Figure 6). Similar conclusion is also established when flow stress in the equatorial plane is considered (Figure 7). Simulated results for stress, strain and velocity at different stages of upsetting are also presented in Figures 8-10.

\section{Conclusions}

The significant conclusions from the present study on

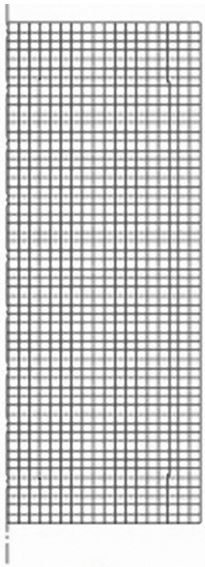

(a)

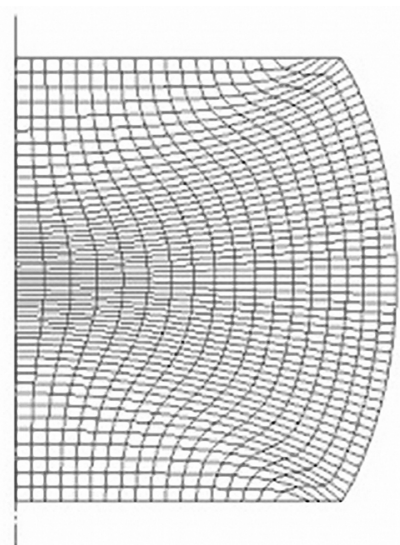

(b)
Figure 5. FEM - model of the sample (a) before and (b) after compression. 


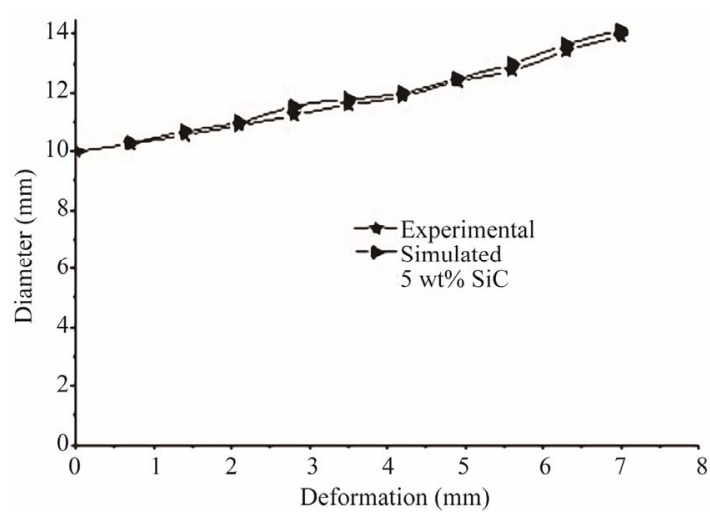

Figure 6. Variation of equatorial diameter with height reduction. Comparison of results from experiment and simulation (5 wt\% SiC).

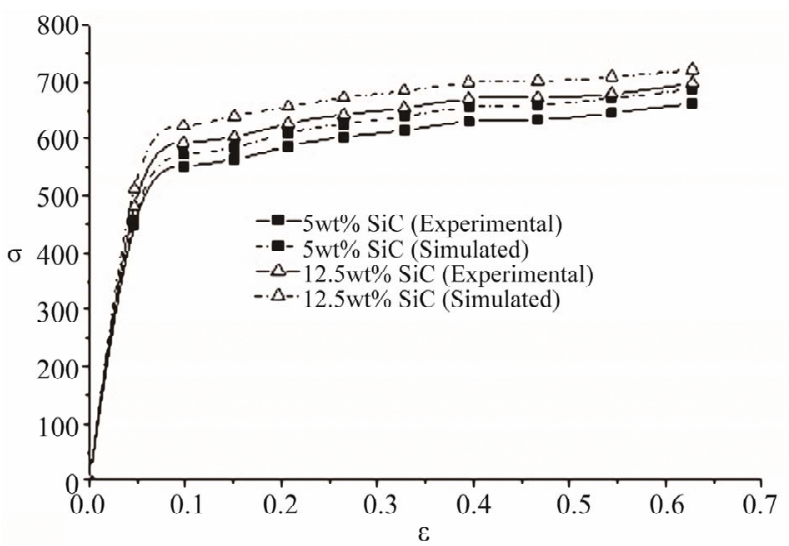

Figure 7. Variation of $\sigma$ with $\varepsilon$. Comparison of experimental and simulated results $(5 \mathrm{wt} \%$ and $12.5 \mathrm{wt} \%$ of $\mathrm{SiC})$.
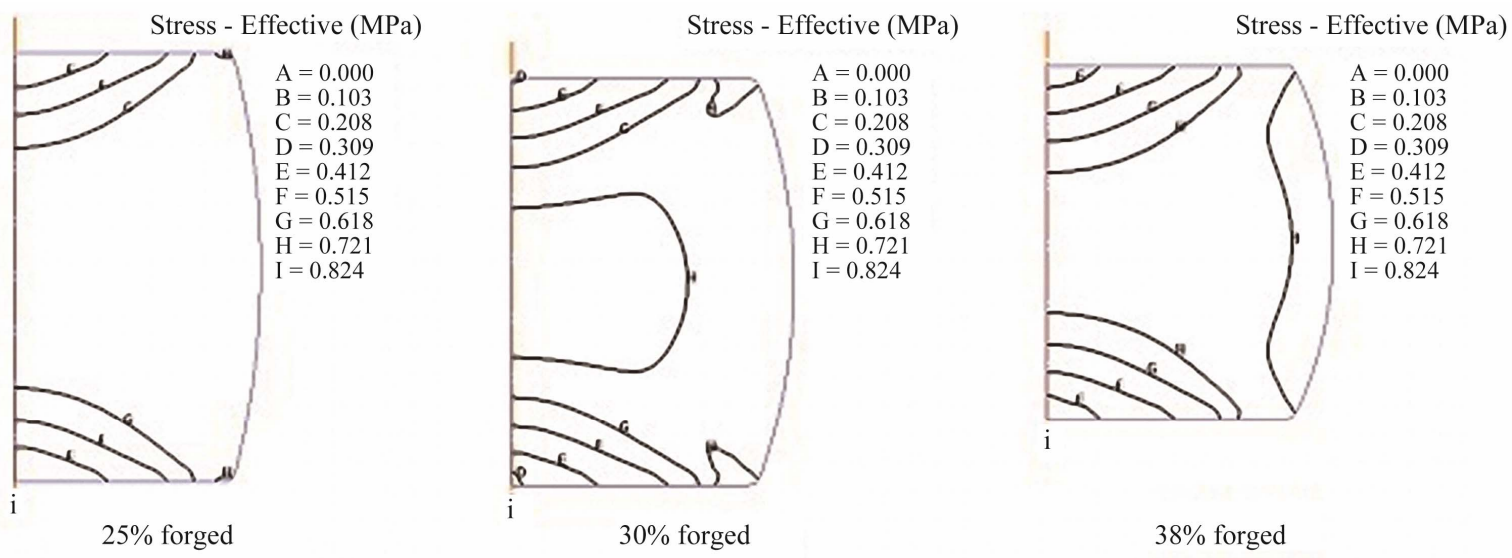

Figure 8. Simulation results showing effective stress distribution at different stages of compression (5 wt\% $\mathrm{SiC})$.
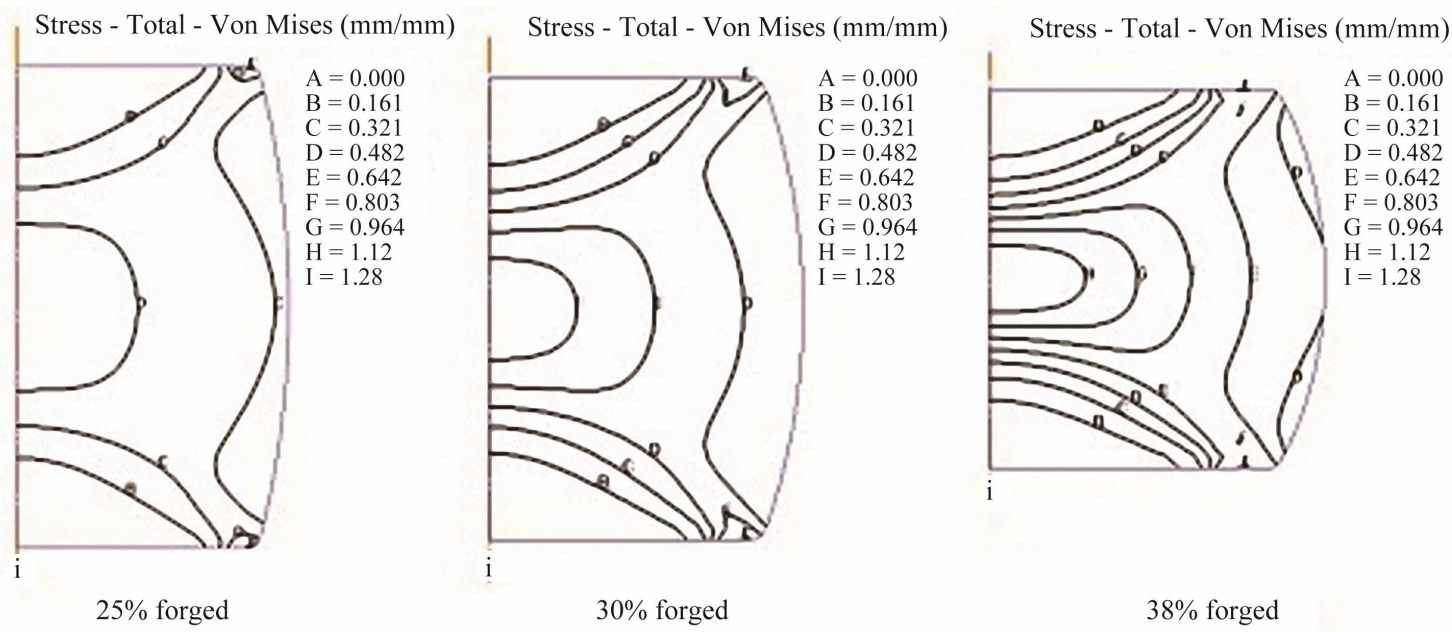

Figure 9. Simulation results showing distribution of Von-mises strain at different stages of compression $(5 \mathrm{wt} \% \mathrm{SiC})$.

LM6/SiC aluminium alloy composites are as follows:

- Homogeneous LM6/SiC aluminium alloy composites can be successfully prepared using liquid metallurgy techniques.
- Both hardness and strength of the composites increase with increase in $\mathrm{SiC}$ content.

- Cylindrical preform can be successfully compressed to a height reduction by $28 \%-32 \%$ without fracture. 

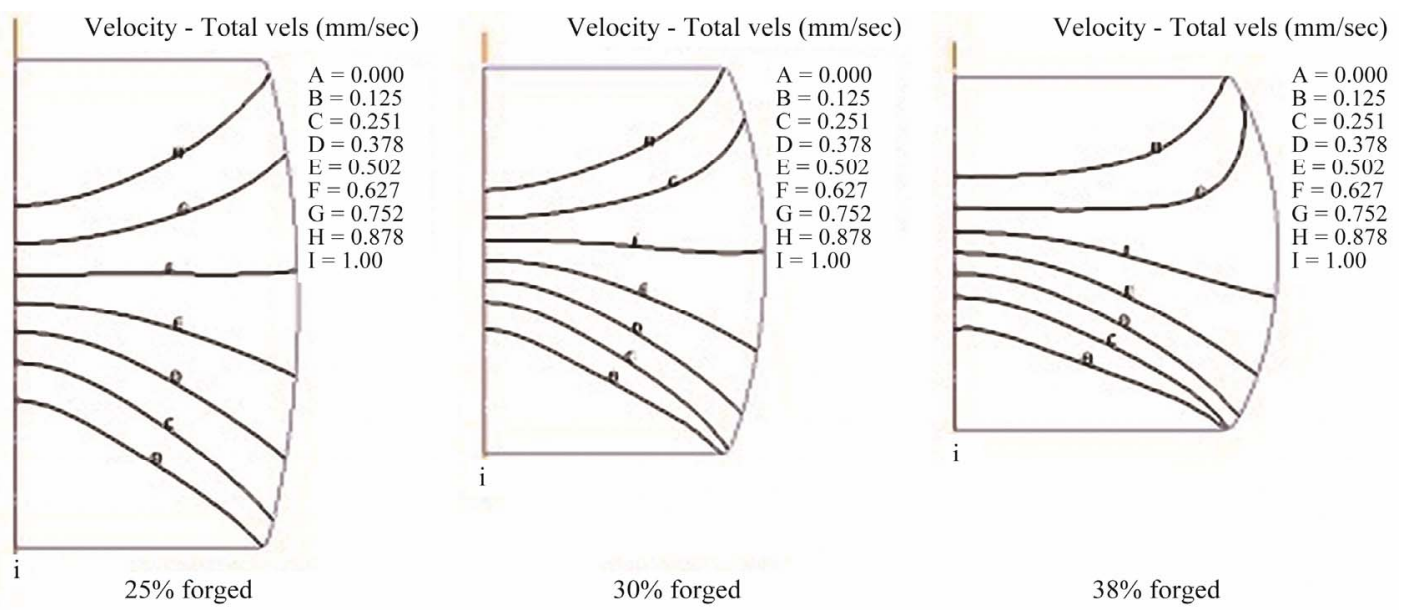

Figure 10. Simulation results showing variation in velocity within the specimen at different stages of compression $(5 \mathrm{wt} \%$ $\mathrm{SiC})$.

Preforms collapse only after a reduction in height by $34 \%-38 \%$.

- Finite element simulation of the deformation behavior of the composite can be carried out as that for a homogeneous material.

- There is close agreement between the simulated results with experiment.

\section{REFERENCES}

[1] G. B. V. Kumar, C. S. P. Rao and N. Selvaraj, "Mechanical and Tribological Behavior of Particulate Reinforced Aluminum Metal Matrix Composites-A Review," Journal of Minerals \& Materials Characterization \& Engineering, Vol. 10, No. 1, 2011, pp. 59-91.

[2] G. B. V. Kumar, C. S. P. Rao, N. Selvaraj and M. S. Bhagyashekar, "Studies on A16061-SiC and A17075- $\mathrm{Al}_{2} \mathrm{O}_{3}$ Metal Matrix Composites," Journal of Minerals \& Materials Characterization \& Engineering, Vol. 9, No. 1, 2010, pp. 43-55.

[3] M. Singla, L. Singh and V. Chawla, "Study of Wear Properties of Al-SiC Composites," Journal of Minerals \& Materials Characterization \& Engineering, Vol. 8, No. 10, 2009, pp. 813-819.

[4] F. L. Matthew and R. D. Rawlings, "Composite Materials: Engineering and Science," Chapman \& Hall, London, 1994.

[5] F. O. gel Bedir, "Investigation of Hardness, Microstructure and Wear Properties of SiC-P Reinforced Al Composites," Proceeding of the 11th International Conference on Machine Design and Production, Turkey, 13-15 October, 2004

[6] V. Laurent, C. Rado and N. Eustathopoulos, "Wetting Kinetics and Bonding of $\mathrm{Al}$ and $\mathrm{Al}$ Alloys on $\alpha$-SiC," Materials Science and Engineering: A, Vol. 205, No. 1-2, 1996, pp. 1-8.

[7] A Martin and J. Llorca, "Mechanical Behaviour and Failure Mechanisms of a Binary Mg 6\%Zn Alloy Reinforced with SiC Particulates," Materials Science and Engineering: A, Vol. 201, No. 1-2, 1995, pp. 77-87.

[8] R. A. Saravanan and M. K. Surappa, "Fabrication and Characterisation of Pure Magnesium-30 Vol.\% SiCP Particle Composite," Matrials Science and Engineering: A, Vol. 276, No. 1-2, 2000, pp. 108-116.

[9] J. Hashim, L. Looney and M. S. J. Hashim, "Metal Matrix Composites: Production by the Stir Casting Method," Journal of Material Processing Technology, Vol. 92-93, 1999, pp. 1-7. doi:10.1016/S0924-0136(99)00118-1

[10] A. Bochenek and K. N. Bbraszezynska, "Structural Analysis of the MgAl5 Matrix Cast Composites Containing SiC Particles," Materials Science and Engineering: A, Vol. 290, No. 1-2, 2000, pp. 122-127.

[11] W. Zhou and Z. M. Xu, "Casting of SiC Reinforced Metal Matrix Composites," Journal of Material Processing Technology, Vol. 63, No. 1-2, 1997, pp. 358-363.

[12] C. N. Devi, V. Mahesh and N. Selvaraj, "Mechanical Characterization of Aluminium Silicon Carbide Composite," International Journal of Applied Engineering Research, Vol. 1, No. 4, 2011, pp. 793-799.

[13] S. Dikshit, V. Gurjar, R. Dasgupta, S. C. Turvedi , K. K. Pathak and A. K. Jha, "Studies on Cold Upsetting Behaviour of AA2014-Based Metal Matrix Composites, FEM Simulation, and Compareison with Experimental Results," Journal of Material Science, Vol. 45, No. 15, 2011, pp. 4174-4179. doi:10.1007/s10853-010-4507-3

[14] C. Badini, G. M. La Vecchia, P. Fino and T. Vale, "Forging of 2124/SiCp Composite Prelimnary Studies of the Effects on Microstructure and Strength," Journal of Materials Processing Technology, Vol. 116, No. 2-3, 2011, pp. 289-297. doi:10.1016/S0924-0136(01)01056-1

[15] H. Sofuoğlu, H. Gedikli and J. Rasty, "Determination of Friction Coefficient by Employing the Ring Compression Test," Transactions of ASME, Journal of Engineering Materials and Technology, Vol. 123, No. 3, 2001, pp. 338-348. doi: 10.1115/1.1369601 